\title{
ENSINO DE CIÊNCIAS E CULTURA LOCAL: UM ESTUDO A PARTIR DAS FALAS DE PROFESSORES DE UM CONTEXTO TEUTO-BRASILEIRO
}

\section{SCIENCE TEACHING AND LOCAL CULTURE: A STUDY OF TEACHERS' SPEECHES IN A GERMAN-BRAZILIAN CONTEXT}

\author{
Dulce Maria Strieder ${ }^{*}$ \\ Anna Maria Pessoa de Carvalho**
}

\begin{abstract}
Resumo
O presente texto aborda os elos entre a cultura e o ensino de ciências, discutindo a existência de elementos da cultura local que permeiam os discursos dos professores de uma comunidade teuto-brasileira, sobre o ensino e a aprendizagem em ciências. $\mathrm{O}$ artigo relata resultados de uma pesquisa que investigou o cotidiano do ensino de ciências no município de Salvador das Missões (RS), colonizado por descendentes germânicos. Os resultados apontam que os principais identificadores culturais, como os valores atribuídos à escola, à família e à língua, continuam vivos no cotidiano da população local e permeiam as falas dos professores sobre temas como a função e os objetivos do ensino de ciências e as posturas adotadas em sala de aula.
\end{abstract}

Palavras-chave: Ensino de Ciências; Cultura Teuto-Brasileira; Formação de Professores

\begin{abstract}
The present text discusses the relationship between the culture and the teaching of Science, focusing the presence of local culture elements in the discourses of teachers from a German-Brazilian community regarding the teaching and learning in Science. It reports results of a research in which we investigated the teaching practice of Science in Salvador das Missões (Rio Grande do Sul - Brazil), colonized by German descendants. The results show that the main cultural identifiers - that is, the values attributed to institutions like the school, the family and the the language - are still alive in the everyday life of the local population. These values are present in the teachers' speeches with respect to themes such as the function and the objectives of Science teaching, as well as in the teachers' attitudes in the classroom.
\end{abstract}

Key-words: Science Teaching; German-Brazilian Culture; Teachers’ Education.

\footnotetext{
* Docente da Universidade Estadual do Oeste do Paraná.

${ }^{* *}$ Docente da Universidade de São Paulo.
} 


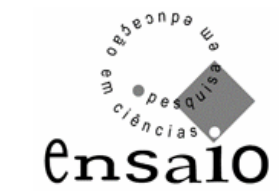

Vol. 11 no1 junho 2009

\section{INTRODUÇÃO}

No meio acadêmico, dentre os inúmeros temas trazidos atualmente para a pauta de discussão, estão presentes de forma marcante as questões culturais e a sua relação com os processos de ensino e aprendizagem. Ocorre cada vez mais, neste meio, a defesa para que, na estruturação das atividades no interior da sala de aula brasileira, ocorram avanços no sentido da inclusão de discussões para além da discriminação de determinados grupos ou minorias presentes na sociedade (discussões estas que, sem dúvida, são também importantes), buscando envolver diretamente o cotidiano dos sujeitos presentes na sala de aula ou os próprios momentos de aula vividos por eles, por exemplo no que diz respeito às relações entre mundos culturais, como a cultura cotidiana destes sujeitos e a cultura científica.

Neste sentido, é importante transitar ainda por estudos que envolvam o pensar sobre como as questões culturais são compreendidas pelos próprios professores de ciências do país, apontando para a diversidade de representações sobre o ensino de ciências em diferentes culturas regionais, sobre como os elementos culturais locais das comunidades em que os alunos e os professores vivem se fazem presentes nas falas sobre as aulas de ciências por eles vivenciadas. Tais questões passam a ser o alvo central de reflexão neste momento.

O presente trabalho traz alguns resultados de uma investigação ampla onde buscou-se elucidar algumas relações estabelecidas entre a cultura local e a cultura da ciência escolar, em especial, elementos da cultura local presentes no discurso dos professores sobre o ensino e aprendizagem na disciplina de ciências. A questão principal que se tentou responder foi: existem elementos da cultura local permeando os discursos dos professores de ciências sobre o ensino e a aprendizagem na disciplina de ciências? Para responder a esta questão, foram escolhidos, como sujeitos da pesquisa, professores da disciplina de ciências em escolas de um município do Estado do Rio Grande do Sul, cuja população apresenta elementos culturais marcantes.

Um total de sete professores participou da pesquisa, cujo instrumento principal de coleta de dados foi a entrevista com roteiro semi-estruturado. A amostra de pessoas entrevistadas é pequena em números gerais, mas bastante significativa para o contexto da comunidade estudada, sendo que, dos seis professores de ciências de $5^{\mathrm{a}}$ a $8^{\mathrm{a}}$ série 


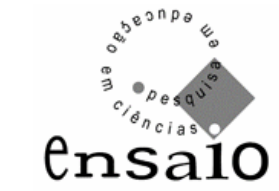

Vol. 11 no1 junho 2009

das escolas presentes no município, cinco foram entrevistados. Também foram entrevistados dois professores aposentados, buscando uma perspectiva histórica da educação local.

A riqueza de informações obtidas resulta em um trabalho que, além de procurar ampliar a reflexão sobre o tema a que se propôs, serve como uma confirmação das distintas realidades educacionais presentes no país.

\section{CULTURA LOCAL E CULTURA CIENTÍFICA}

Na sociedade atual, estão presentes fortemente as dúvidas sobre como tornar possível a convivência pacífica, entre pessoas e povos de diferentes formas de pensar, de agir, de organizar-se, com diferentes valores e compreensões de mundo e de homem, comunicando-se intensamente, sendo ambos conhecedores dos elementos do outro, sem, entretanto, isto significar a perda das características de identificação de cada grupo.

Com o aumento vertiginoso, a partir do século XX, da comunicação entre as pessoas e os povos e os interesses políticos e econômicos, a super-valorização de uma única cultura começa a ser suprimida de forma a permitir o diálogo. Por outro lado, além da busca pela compreensão e aceitação do diferente, se intensifica o trabalho para a definição de identidades dos diferentes grupos étnicos, no qual a etnicidade é compreendida não como algo rígido, mas como um processo que se constitui nas práticas sociais e do seu domínio não derivam “[...] as diferenças culturais empiricamente observadas, mas as condições nas quais determinadas diferenças culturais são utilizadas para estabelecer a diferença entre in-group e out-group” (KREUTZ, 2003b, p. 83).

Assim, para Kreutz, torna-se relevante estudar para além das diferenças entre grupos, observando as condições que dão origem às distinções étnicas e à sua articulação com mudanças culturais, o que permite compreender inclusive os motivos que levam à reivindicação da identidade por um grupo ou à atribuição de características a ele, por outros.

Ao pensar na cultura “[...] como um patrimônio de conhecimentos e competências, de instituições, de valores e símbolos, constituído ao longo de gerações 


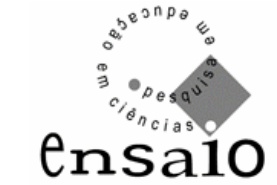

Vol. 11 no1 junho 2009

[...]” (MEYER, 1999, p. 75), há que se considerar que, naturalmente, cada sujeito, pelos processos de interação, está livre de limites culturais herméticos, assumindo e modificando alguns elementos da variada cadeia cultural.

A compreensão e a valorização das fronteiras étnicas, as suas origens e conseqüências, bem como o conteúdo cultural dos grupos, auxilia na superação da idéia de cultura única elitizada, além de permitir uma reflexão profunda no intuito de afastar os riscos da constituição de uma nova cultura universal, provocada pela atual situação de diluição dos limites rígidos que separavam territórios culturais específicos.

Diferentes instâncias da sociedade estão constituindo e reforçando objetivos e ações próprias, construindo ou reconstruindo as suas identidades. A escola, neste contexto de mudança na compreensão de cultura e etnicidade, tem encontrado dificuldades em operar em um meio com a presença valorizada de diferentes culturas. Restam ainda, por exemplo, muitas dúvidas sobre as formas de levar os alunos a imergir na cultura científica, inserção de extrema relevância para que os sujeitos compreendam elementos importantes do mundo em que vivem, sem, entretanto, destruir as suas próprias culturas.

Os possíveis processos que visem facilitar a imersão na cultura científica por meio da escola, que representa uma das instâncias capazes de contribuir significativamente para tal fim, tornam-se mais coerentes se levarem em consideração a reflexão acerca da cultura subjacente às práticas associadas à educação formal. Para além disto, a ciência e a tecnologia compreendidas enquanto construções humanas, determinando e sendo determinadas pela sociedade, são integrantes da cultura do mundo ocidental, ainda que possuam toda gama de símbolos e significados próprios.

A formação da cultura científica necessita abarcar uma concepção mais ampla do que aquela que julga suficiente para a sua constituição a passagem linear do conhecimento científico e tecnológico dos cientistas para o público em geral. Segundo Vogt e Polino,

A cultura de ciência e tecnologia não consiste somente em um estoque de conhecimentos codificados que o indivíduo incorpora, mas também implica outras dimensões não menos relevantes: práticas científicas e tecnológicas institucionalizadas; práticas de "racionalidade" científica e tecnológica aplicadas a diferentes âmbitos institucionais ou apropriação da ciência e tecnologia em 


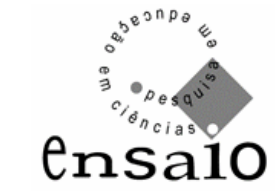

Vol. 11 no 1 junho 2009

tais âmbitos (governo, ditames de normas, educação, comunicação, esporte, produção de bens e serviços etc.); distribuição de informação e conhecimento na cultura geral; dimensão quantitativa do sistema científico (recursos humanos, investimento, organizações, patentes etc.); mecanismos de sustentabilidade da instituição científico-tecnológica; e orientação da atividade científico-tecnológica, isto é, uma sociedade estará mais ou menos cientifizada na medida em que a questão "para onde se dirigem a ciência e a tecnologia” constitua um tópico da cultura geral e do debate social. (VOGT e POLINO, 2003, p. 41-43).

Os processos de formação da cultura científica em diferentes sociedades podem levar a resultados diversos, na medida em que “[...] sua recepção, apropriação e emprego são processos localizados socialmente e sujeitos tanto às especificidades culturais de cada sociedade quanto à situação social histórica e concreta destas”. (VOGT e POLINO, 2003, p. 31-33). Neste sentido, é bastante relevante que a intenção de trabalhar por sobre a imersão na cultura científica esteja associada a um conhecimento não apenas das dimensões próprias abarcadas por ela, mas também ao conhecimento amplo da cultura geral da sociedade ou do grupo junto ao qual se pretende atuar.

Promover a interação no interior da escola, de variadas concepções, apontando para a sua validade e também para os seus limites, evitando juízos de valor discriminatórios, certamente contribuirá para uma postura crítica e interrogadora por parte do aluno, e uma postura ética por parte do professor, atitudes essenciais para o processo de formação. Ela pode assim auxiliar na superação, por exemplo, de visões pejorativas algumas vezes associadas a saberes regionais oriundos diretamente de uma cultura local, que ainda que consigam, a duras penas, sobreviver e que, muitas vezes são reconhecidos pelos próprios integrantes locais desta cultura como saberes inferiores ou de valor limitado.

Para aqueles que fazem parte das classes dominadas, ou que provêm delas, a diversidade é, com freqüência, um handicap, uma deficiência; sua experiência, seus saberes, sua "cultura" têm uma amplitude limitada, um valor local; não o são reconhecidos ou o são em pequena medida fora de seu meio social profissional e geográfico de origem. (GRIGNON, 1998, p. 183). 


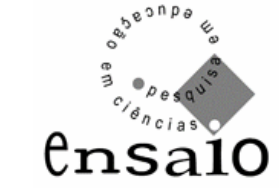

Vol. 11 no1 junho 2009

No interior da escola, a própria existência da cultura do aluno, a do professor e a cultura científica ou uma cultura científica escolar (já que ao estar na escola as próprias formas de interação já a modificaram em relação ao meio científico) implica a necessidade da atuação considerando o meio como de diversidade cultural. Assim, o foco em um trabalho de interação entre culturas é relevante para além das diferentes culturas locais e que são trazidas para o interior da escola por alunos e professores, mas na busca de interação entre estas culturas e a cultura da ciência escolar.

Para que a escola possa direcionar ações em busca de integrar-se na perspectiva de valorização de aspectos culturais de alunos e professores, um grande passo, e talvez o primeiro, diz respeito à formação de professores. A formação de profissionais da educação pautada em tal estrutura poderia contribuir intensamente na valorização dos conhecimentos e das concepções que os alunos e os professores trazem, relativos desde a sua visão ampla de mundo até os conteúdos a serem trabalhados em sala de aula. Acredita-se que identificar e compreender profundamente as concepções de alunos e dos próprios professores tornar-se-á facilitado a partir da consciência dos motivos e das interações que levaram à constituição de tais crenças e da possibilidade da interferência de aspectos da cultura local.

\section{NUANCES HISTÓRICAS E CARACTERIZAÇÃO GERAL DA ÁREA DE ESTUDO}

O contexto teuto-brasileiro do município de Salvador das Missões, RS, é marcado por elementos culturais que são fruto de um longo processo de constituição de suas comunidades, desde aqueles trazidos inicialmente como herança da Alemanha, de onde emigraram os ancestrais dos que habitam as comunidades investigadas, até as suas modificações em virtude do cotidiano encontrado na colonização e no posterior contato intensificado com culturas distintas.

Localizado na região Noroeste do Estado do Rio Grande do Sul, Salvador das Missões possui território total de $94,82 \mathrm{~km}^{2}$ e é composto por 10 comunidades. A população, segundo dados levantados em 2000 pelo Instituto Brasileiro de Geografia e Estatística (IBGE), é composta por 810 famílias, num total de 2665 habitantes, dos quais 1815 são moradores da zona rural e apenas 850 são moradores da zona urbana. 


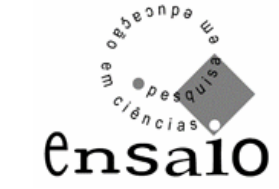

Vol. 11 no1 junho 2009

Daqueles habitantes com rendimentos, $77 \%$ os têm em valores mensais iguais ou inferiores a 3 salários mínimos. Ainda com referência nos dados do IBGE, o Índice de Desenvolvimento Humano (IDH) do município é de 0,810, valor que se enquadra na faixa de IDH alto.

A sua emancipação política ocorreu no ano de 1992, sendo que até então pertencia ao município de Cerro Largo, anteriormente, denominado de Sêrro Azul, uma das colônias novas fundadas na segunda fase de ocupação do RS pelos imigrantes de origem germânica. Na colonização da comunidade que abriga a sede do município de Salvador das Missões a primeira preocupação na organização da vida coletiva da comunidade em formação foi a estruturação de um espaço para a educação e a assistência religiosa, situação não diferente da grande maioria das colônias teutobrasileiras fundadas a partir de 1824 no Estado do Rio Grande do Sul.

Nas colônias teuto-brasileiras, as escolas inicialmente fundadas, denominadas de escolas paroquiais em função de seu vínculo com a religião, eram construídas e mantidas pelos próprios integrantes das comunidades. Os professores, com amplas funções religiosas e sociais, eram, em geral, escolhidos entres os moradores locais. Sua atuação era totalmente direcionada para a comunidade, reforçando seus valores culturais. Assim, a língua utilizada na alfabetização era o alemão e a atuação era fortemente associada à formação dos valores morais e religiosos.

A implantação da escola pública local ocorreu em 1939, em substituição à escola paroquial. Neste momento, o professor atuante na escola da comunidade interrompeu a atividade educativa por não ter condições de atender às exigências relativas à educação, como exemplo, a obrigatoriedade do ensino na língua portuguesa, implementadas durante o processo de nacionalização com auge em 1938. (KÜLZER, 2004).

Assim como relatado acima para a comunidade de Salvador das Missões, que abriga a sede do município, cada uma das comunidades que o integra tem história similar de fundação.

No ano de 2005, a estrutura educacional do município de Salvador das Missões contava com 4 escolas municipais de ensino fundamental, das quais 2 possuem da préescola a $8^{\text {a }}$ série, e outras 2 possuem apenas os primeiros ciclos do ensino fundamental, onde estão matriculados 209 alunos no total. Está presente, na sede do 


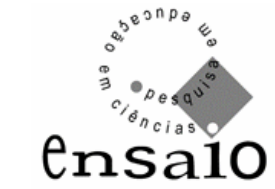

Vol. 11 no1 junho 2009

município, uma escola estadual que atende desde crianças da pré-escola até o ensino médio, com 330 alunos matriculados.

Os professores que atuam na disciplina de ciências de $5^{\mathrm{a}}$ a $8^{\mathrm{a}}$ séries do ensino fundamental são 6 no total, distribuídos em duplas nas escolas. A formação de 5 destes é em Cursos de Ciências, de licenciatura curta, com posterior habilitação em Matemática ou em Biologia, além de uma professora com licenciatura no Curso de Biologia.

Inúmeras modificações relativas à cultura local e os seus vínculos com a educação, certamente estão em curso. Especificamente para o ensino de ciências, interessantes visões estão presentes, como aquelas acerca do valor a ele atribuído e a sua função para as crianças das escolas locais e para toda a comunidade. Estas poderão ser melhor apontadas e exploradas a partir da apresentação, na seqüência, de alguns dos dados coletados em campo e de sua análise. Ressaltamos que, em função do restrito espaço para discussão, característica própria dos artigos, apresentaremos apenas algumas falas capazes de representar as opiniões que aparecerem de forma majoritária nas entrevistas.

\section{O ENSINO DE CIÊNCIAS E A CULTURA LOCAL NAS FALAS DOS PROFESSORES}

Em busca de aprofundar a compreensão sobre o nível em que os elementos da cultura local permeiam as formas de pensar dos professores de ciências entrevistados, em cada uma das entrevistas procurou-se questionar sobre as relações entre o ensino de ciências e o contexto em que a escola se insere, em especial nos seus aspectos culturais. Sobre o ensino de ciências nas escolas de ensino fundamental local, os professores dizem:

\section{Entrevistado 7}

(...) esta área de ciências para mim é muito gratificante porque isso ajuda na vida do dia-a-dia... ajuda a gente a se defender tanto na agricultura e ajuda no sustento também... porque o agricultor hoje depende da lavoura e quem sabe plantar ele ainda colhe melhor do que aquele que simplesmente despeja sementes no chão... (...) 


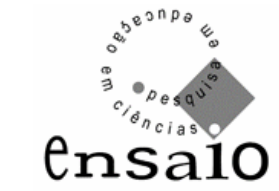

Vol. 11 no1 junho 2009

O entrevistado coloca a sua posição sobre a função do ensino de ciências já no início da entrevista, quando, a partir da questão inicial, ele é levado pela entrevistadora a falar sobre as suas origens e a sua formação profissional. A sua colocação sobre onde está o valor do ensino de ciências é, portanto, espontânea e direciona para a contribuição da escola, por meio deste ensino de ciências, na melhoria das atividades do cotidiano, buscando tornar os alunos pessoas mais aptas para o trabalho na agricultura. No segmento abaixo este mesmo entrevistado complementa a fala anterior.

\section{Entrevistado 7}

Ela está voltada a... a... na verdade aos interesses da comunidade neste sentido né... porque mesmo em are/ em termos de plantas medicinais e tudo ela contribui muito... questões de alimentação... higiene e saneamento básico... tanta outra coisa

Os vínculos entre o trabalho na agricultura e o ensino de ciências é facilmente apontado quando as questões da entrevistadora direcionam para o papel do ensino de ciências, especificamente para as crianças daquele local. Assim, dois dos entrevistados comentam:

\section{Entrevistado 2}

Ah:: mas na agricultura é tudo... o agricultor tem que saber ciência... a ciência é a base de... de toda a vida... da vida da planta... da vida animal... da vida... da nossa própria vida... tudo... tudo... a ciência é uma necessidade absoluta para todos..

Nesta fala está presente a defesa da importância de os moradores locais terem acesso aos conhecimentos que o ensino de ciência pode oferecer. A importância de tal estudo é direcionada para a compreensão daqueles elementos que se fazem presentes no cotidiano dos agricultores.

\section{Entrevistado 5}

Na vida... sim... porque as crianças levam para casa a questão da separação do lixo... a questão que estava....algumas famílias sempre ainda fizeram composto... mas outras acabaram esquecendo e você falando disso eles levam de volta para casa e alguns até praticam... (...) 


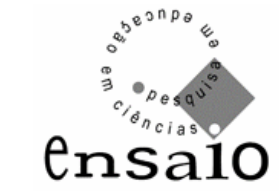

Vol. 11 no1 junho 2009

Neste segmento, o foco de atenção está centralizado na visão de que este ensino se vincula a esta comunidade por, em muitas situações, oferecer conhecimentos capazes de modificar posturas da população relativas ao seu cotidiano, especialmente no manejo com a propriedade agrícola.

Os professores também estabelecem vínculos entre o ensino de ciências e a cultura local apontando que o conhecimento dos alunos sobre a lida com a terra e as plantas contribui para o ensino e a aprendizagem em ciências.

\footnotetext{
Entrevistado 4

(...) como que a lillichia aqui... esta fruta... que ninguém conhece... não adianta eu falar de lichia... adianta eu falar do araticum etc... pegar as folhas que nós conhecemos ali fora... e o alemão como... como ele é um desbravador da agricultura ele tem MUITO contato com a terra... (...)
}

Segundo este entrevistado, é importante que se aproveite para o ensino de ciências do conhecimento, por exemplo, de plantas que os alunos já possuem, podendo com isto tornar as aulas contextualizadas.

O papel atribuído ao ensino de ciências nas escolas locais aparece associado, nas falas dos entrevistados, àquilo que é capaz de contribuir para a melhoria da realidade local, ou tendo a comunidade na base da definição dos objetivos da atividade de ensino, estando comprometido com as suas necessidades, ou, então, ao ter o seu currículo previamente estabelecido, ser ao menos capaz de, por meio de alguns conteúdos, fornecer informações ou modificar posturas tidas no cotidiano da comunidade.

Autores como Kreutz (1994a) e Rambo (1996) defendem que, nas escolas paroquiais ou comunitárias implantadas pelos colonizadores, a formação do aluno enquanto cidadão era direcionada para atender à possibilidade de integração plena nas próprias comunidades, sendo capazes de participar ativamente da sua edificação. A cidadania se expressava através da constituição de uma comunidade promissora, obtida pelo trabalho dos moradores locais.

A fala dos entrevistados, ainda que oriunda de uma realidade já com modificações daquela presente no momento das escolas comunitárias ou paroquiais, parece trazer subjacente ainda semelhanças com as descritas pelos autores acima. 


\section{8 \\ ensa10}

Vol. 11 no 1 junho 2009

Os papéis representados pela escola e pelo professor também não estão distantes do que é considerado para o ensino de ciências. Para a atuação destes, também está presente, como instância definidora, o contexto vivido localmente. Assim, o valor da escola não está apenas nos conhecimentos específicos nos quais forma os alunos, mas como uma instância sobre a qual todos da comunidade têm o seu olhar, sendo um elo entre estes, um objetivo e preocupação comum.

\section{Entrevistado 1}

Eu ainda acredito que a escola é a alma de uma comunidade... se ela não funcionar... nada funciona... e é por ali que vem a educação... as mudanças que nós queremos... através da escola...(...)

Para os entrevistados, a escola tem papel na estrutura da organização da comunidade como um todo. As falas deixam transparecer que esta instituição representa um patrimônio comum a toda comunidade de moradores, sendo assim um motivo de diálogo entre estes moradores, um interesse comum que os leva a se unir. Esta união se torna mais distante para a grande maioria das preocupações e ações cotidianas, por estas estarem associadas ao trabalho individualizado de cada família no interior das suas propriedades.

O funcionamento da escola representa um espelho para a organização de toda a comunidade, na medida em que ela é um forte elemento de identidade cultural. Como diz Rambo: "Os colonizadores alemães, desde muito cedo, elegeram a escola como um dos meios mais eficazes do combate ao que consideravam decadência cultural e religiosa”. (RAMBO in FIORI, 2003, p. 69).

O valor atribuído à escola local pelos professores de ciências e o leque de funções aparentemente dadas a ela auxiliam a manter vivo também o reconhecimento da importância do papel do professor. Em suas falas, os professores de ciências destacam que, apesar de a realidade local ter sofrido significativas modificações, no que diz respeito à função e valorização do professor, este ainda é uma referência para as comunidades e, assim sendo, deve manter posturas que façam jus ao reconhecimento dado pelos moradores locais.

\section{Entrevistado 7}




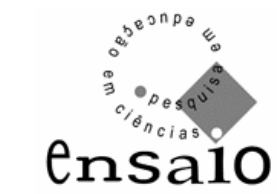

Vol. 11 no1 junho 2009

Olha eu acho que uma vez a gente mostrando quem a gente é... isto pega... pega... é como um copo... se tu deixa cair o copo de vidro e ele quebra para consertar é difícil... então o melhor é sempre mostrar o que você é... dentro da escola e fora dela... eu como um professor jamais posso ir num bolicho e ficar me embebedando... não dá para pregar moral sem cuecas... este é um fato... então se tu nunca te queimou frente a uma comunidade... você tem o respeito e o trabalho anda...

Neste segmento podemos destacar, em primeiro lugar, o valor que o entrevistado dá à imagem que a comunidade tem dele enquanto pessoa, imagem que, segundo ele, é a base de sustentação para o respeito à figura do professor. Em segundo lugar, é interessante notar a relação estabelecida entre o respeito da comunidade pela figura do professor e o vínculo com o bom andamento do seu trabalho na educação. Surge aí a noção de parceria ou de troca entre as pessoas da comunidade e o professor. Este último, ao ser parceiro nos valores, por exemplo, morais da comunidade, esta também lhe é parceira nas questões em torno da educação.

A importância do exemplo que o professor dá para a comunidade, por meio das suas atitudes fora da escola, também é destacada por outros entrevistados, como no segmento abaixo:

\section{Entrevistado 5}

(...) por você falar que você também faz... por exemplo que você aproveita as frutas em casa... a:: tem aquela coisa... "ah... se a professora faz porque que nós também não vamos fazer?”... sabe... então a questão do exemplo...

O entrevistado, neste caso, não relaciona diretamente o valor das suas atitudes frente à comunidade com seu trabalho na escola, mas a importância das atitudes enquanto pessoa respeitada, portanto formadora de opinião, para a geração de atitudes semelhantes em relação a diferentes questões mesmo que externas ao ambiente escolar.

Abaixo apresentamos outro trecho que traz novas informações sobre o que é considerado como função do professor local:

\section{Entrevistado 4}

(...) tu vai aqui por exemplo praticamente todos têm televisão mas eu fico assim abismado... triste... quando alunos de $5^{\text {a }}$ série me 


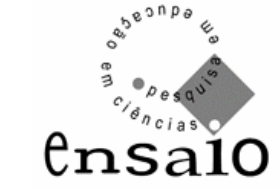

Vol. 11 no1 junho 2009

assistem programas de TV após as 11:00h da noite... e isto me obriga a eu também assistir certos programas de noite para eu saber em que ponto eles estão... para eu poder dar a orientação...

Neste segmento, um ponto bastante interessante trazido para a discussão é a atitude que é defendida pelo entrevistado de que, se os seus alunos estão assistindo a alguns programas de televisão, ele, enquanto professor, sente-se na obrigação de também assisti-los, não enquanto forma de obtenção de alguma informação técnica ou de conteúdo curricular para aprofundar ou incrementar a sua aula, mas como forma de possibilitar uma orientação associada à estruturação da personalidade do aluno. Está presente nesta fala a noção de responsabilidade da escola e do professor na formação do caráter do aluno, tendo como modelo a própria comunidade que integra, buscando evitar que este aluno se torne agente de modificações da estrutura ali implantada. Aparentemente está em jogo a função da educação na manutenção da harmonia em torno dos valores culturais locais.

Neste sentido, ainda que com mudanças consideráveis nas recentes décadas, no significado da figura do professor para a comunidade local, ele continua ocupando uma função com nuances do descrito por Kreutz, ao referir-se aos professores paroquiais: "Ele foi um elemento de unificação, um agente de síntese e promoção das percepções do grupo humano no qual se inseria ativamente, seja no campo social, político, religioso e cultural.” (KREUTZ in FIORI, 2003a, p. 158).

O relato dos entrevistados com ênfase na valorização da figura do professor local não parece ter sido adotada como uma maneira de tirar o foco das dificuldades encontradas, pois estes não deixam de mencionar que, no seu cotidiano, também enfrentam problemas. Entre tais problemas, destacam as mudanças no comportamento dos alunos, que agora são mais agitados, muitas vezes prejudicando o seu potencial de concentração e a estrutura planejada para o ensino em sala de aula. O desinteresse dos alunos pelo estudo também foi alvo de discussão, além das dificuldades, nas aulas de ciências, para a leitura e compreensão de textos.

Cabe ressaltar que a própria forma de os professores falarem sobre as suas dificuldades não envolveu demonstrações de desânimo com a profissão ou alguma demonstração de vontade de migrar para outra profissão. Também não se fez presente nenhum comentário sobre possível interesse em mudar de escola ou de local de 


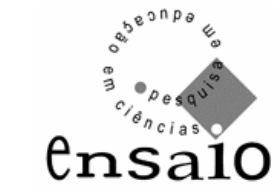

Vol. 11 no1 junho 2009

moradia. O segmento apresentado abaixo representa bem as posturas demonstradas pelos professores durante as falas.

\begin{abstract}
Entrevistado 7
Olha... eu acho que quem tem vontade e quem gosta da profissão essas pequenas dificuldades não representam nada né... eu na verdade gosto do meu trabalho... gosto de dar uma aula de ciências... matemática é mais fácil ainda né... então eu não vejo grandes dificuldades frente aos alunos... a gente tem dificuldades assim é:: na verdade porque aqui o povo... o povo é bastante simples e com poucos recursos financeiros... conforme isto a gente tem que fazer... realizar o trabalho... mas no mais assim eu adoro o trabalho que eu tenho...
\end{abstract}

Mais uma vez está presente o vínculo entre o trabalho realizado em sala de aula e a realidade vivida pela comunidade a qual a escola atende. Assim, o papel do professor de ciências também ultrapassa os limites da sua atuação em sala de aula, tendo o seu reconhecimento pelos moradores locais, baseado na imagem enquanto pessoa e professor que transparece em todos os momentos e instâncias locais. O seu comportamento é analisado na escola, mas também fora dela, e o apoio da comunidade é embasado no modelo de postura que representa.

Os maiores intervalos de tempo nas discussões sobre a cultura local e os momentos em que os entrevistados se sentiram mais à vontade para falar foi sobre a fala bilíngüe dos alunos. Os professores entrevistados relatam que, atualmente, as crianças em geral falam o português, mas mantêm um intenso contato com a língua alemã através das falas dos pais e avós ou demais pessoas com quem se relacionam, fazendo com que compreendam totalmente o dialeto alemão.

Em relação ao ensino de ciências, o que os professores apontam é que o fato de falar o alemão, tanto o professor quanto a criança, auxilia no ensino e na aprendizagem, pois o uso durante as aulas de termos em alemão permite que o aluno estabeleça pontes entre o que está estudando e o seu cotidiano. A principal referência é de que, por vezes, os alunos não entendem ou não associam o conteúdo com algo conhecido do seu contexto, pelo fato de, neste último, o nome ou termo ser conhecido apenas em alemão. Assim, ao traduzir termos do conteúdo curricular para o alemão, o aluno faz a associação com o que conhece. Um exemplo das falas que apontam para tal fato está no segmento abaixo. 


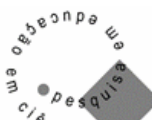 \\ ensa10}

Vol. 11 no 1 junho 2009

\section{Entrevistado 4}

(...) então dentro deste contexto facilita... a gente pode muitas vezes dizer uma coisa na aula de ciências em alemão... "olha... isto ali que você tá enxergando" que ele não se atina por nome a gente diz em alemão esses nomes "ah... sim... isto... ta... ok" se flagram direto né... (...)

A fala de outro entrevistado também se aproxima da anterior, descrevendo situação semelhante e ressaltando que considera o uso de termos em alemão durante as aulas de ciências de grande importância, pois facilita a associação do conteúdo com os conhecimentos prévios dos alunos. Este entrevistado diz ainda que utiliza procedimento semelhante com alunos de outras culturas, buscando conhecer mais sobre a sua realidade, incentivando-os a falar os termos próprios utilizados para diferentes animais e plantas.

\section{Entrevistado 5}

Sim... há... inclusive eu estimulo até procurar saber tanto dos nossos alunos vindo da barranca do rio como dos alunos que são de origem alemã... então como eu uso muitas vezes o termo em alemão para que eles lembrem de que planta a gente está falando... (...) Ela ajuda... principalmente para que o aluno saiba do que você está falando...(...)

É interessante considerar que, de forma geral, os professores entrevistados deixam transparecer um certo temor de que a língua local seja classificada como um entrave para a aprendizagem em ciências ou como uma desvantagem das escolas locais em relação a escolas de outras regiões. Um exemplo é o segmento abaixo, onde a questão feita pela entrevistadora sobre a interferência ou não da cultura local nas aulas de ciências mereceu uma defesa imediata pelo entrevistado de que esta cultura não prejudica tais aulas.

\section{Entrevistado 7}

Eu não sei... para mim o alemão é uma vantagem... dominar mais de uma língua isto é ótimo... quanto mais melhor... é um privilégio de certa forma ali o povo ser alemão para nós porque o português dali a pouco vai engrenar naturalmente... vai fluir... e tudo que... estes costumes que este povo tem... eles ajudam a viver melhor também de certa forma... então eu não sei se tem problema nisto... tem solução nisto 


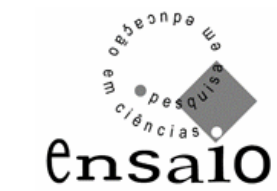

Vol. 11 no 1 junho 2009

Subjacente à defesa tão veemente de que a língua falada no local apenas traz vantagens, podem estar presentes aí resquícios das perseguições e discriminações sofridas no passado, quando a cultura teuto-brasileira foi classificada como aliada aos inimigos do Brasil. Não tão distantes assim estão situações constrangedoras enfrentadas ocasionalmente, no contato com pessoas de diferentes origens, quando o sotaque, a forma de andar ou outras características, algumas vezes, se tornaram motivos de comentários.

\section{CONSIDERAÇÕES FINAIS}

A escola, a família, a língua, a religião e o convívio em comunidade são os identificadores centrais da cultura teuto-brasileira. Estes identificadores estiveram presentes no processo de colonização e continuaram de grande valor nos momentos subseqüentes a tal processo. A fala sobre estes, trazidos para discussão entre professores de ciências por meio da pesquisa realizada, mostrou que, apesar das intensas modificações processadas nas comunidades teuto-brasileiras investigadas, desde a colonização até a presente data, eles continuam vivos no cotidiano daquelas pessoas e, por conseqüência, permeiam as suas representações sobre os mais diferentes temas, inclusive no que diz respeito à sua profissão.

É possível, assim, dizer que o intenso valor atribuído aos identificadores da cultura e os vínculos estabelecidos entre eles são os principais elementos da cultura local que permeiam as falas dos professores de ciências do campo investigado, influenciando as suas formas de pensar sobre, por exemplo, os papéis da educação, do professor e do ensino de ciências.

A educação, voltada hoje de forma explícita a formação para à cidadania, objetivo expressado pelos investigados no potencial dos alunos locais em obter acesso a um cotidiano melhor, traz ainda subjacente a formação nos valores morais, papel central da educação promovida nas escolas paroquiais.

O professor, anteriormente orientador e representante da comunidade em todos os setores, tem atualmente um papel mais reduzido. Entretanto, ele ainda é uma pessoa de referência e respeitado, para o que deve zelar pela sua imagem pessoal e profissional frente à comunidade em todos os momentos. 


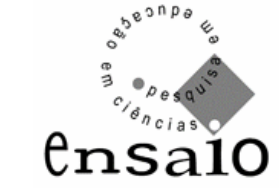

Vol. 11 no1 junho 2009

As falas sobre o ensino de ciências, foco de atuação profissional dos investigados, trazem subjacentes os modelos de educação e de professor por eles expressados. Neste sentido, o papel central do ensino de ciências está naquilo que ele pode contribuir para a melhoria do cotidiano local dos alunos, sendo que este cotidiano é considerado como intensamente vinculado aos conteúdos desta disciplina. O convívio dos alunos com o meio ambiente é fator compreendido como de facilitação da aprendizagem em ciências e também elemento que faz esta disciplina de extrema relevância, um caminho para modificar posturas da comunidade local consideradas equivocadas.

Os conhecimentos prévios sobre conteúdos das ciências, construídos pelos alunos no seu cotidiano em família ou em comunidade, envolvem a fala da língua alemã, presente, por exemplo, na sua aprendizagem em família dos nomes de plantas, animais, e das ações de manejo com estes, entre outros. Assim, no ensino de ciências, ao tentar estabelecer pontes entre o conteúdo curricular e estes conhecimentos prévios dos alunos, recorre ao uso da tradução. Nas falas dos professores, a necessidade de uso da tradução não é um elemento gerador de maior dificuldade no ensino e aprendizagem. Ao contrário, a possibilidade de uso da tradução de termos é um fator capaz de tornar o conteúdo da disciplina de ciências significativo para os alunos, estabelecendo elos entre o conhecimento prévio local e o conhecimento científico, portanto é um diferencial do ensino local, de grande contribuição para a aprendizagem. Com tais argumentos, evita-se que a língua falada, integrante da identidade cultural local, seja caracterizada como geradora de dificuldades.

As comunidades investigadas têm elementos culturais próprios, frutos parciais do processo de colonização e (re)elaborados a partir da integração vivenciada desde aquele processo. Pela similaridade das suas características de colonização e integração com outras comunidades presentes regionalmente, pode ser considerada uma representante autêntica de inúmeras outras comunidades. Entretanto, é importante frisar que não consideramos que são apenas as comunidades investigadas ou aquelas de origem teuto-brasileira que valorizam a escola, a religião, a família, a comunidade, e onde tais instâncias se fazem presentes com fortes elos. É possível que tais características estejam presentes em inúmeras comunidades nacionalmente, das mais diversas origens culturais. 


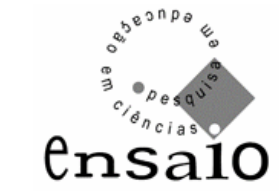

Vol. 11 no1 junho 2009

O foco central aqui apresentado, fazendo-nos repetir, é de que os elementos de origem cultural local se fazem presentes nas falas dos professores e, assim, se encontram vinculados à formação da cultura científica por meio do ensino de ciências. Buscamos caracterizar, para as comunidades investigadas, quais são os elementos centrais da cultura local presentes nas representações dos professores e as possíveis origens de tais elementos. Em comunidades distintas das investigadas, os mesmos elementos podem se fazer presentes, em outras formas e origens, ou ainda inúmeros elementos diferentes.

Acreditamos, assim como Candotti, que “[...] devemos dar maior atenção à cultura, às condições, aos hábitos, aos jogos, às histórias e às tradições locais quando ensinamos ciências.” (CANDOTTI, 2002, p. 23). A própria formação para a atividade de ensino de ciências precisa levar em consideração que, por meio da atenção a tais aspectos, poderá construir um caminho para que possamos elaborar melhor aquilo que queremos ensinar, adaptando-o à realidade local em que o ensino será efetivado. Nesta formação é preciso levar os formandos, entre outros aspectos, a conhecer sobre/a ciência, sobre o ensino de ciências e sobre a cultura local, tendo possibilidade, assim, de adequar as atividades em sala de aula ao “[...] modo de imaginar e representar e também aos exemplos e histórias que encontramos no cotidiano do lugar onde vivemos. E isso, mesmo naqueles casos em que é nossa intenção propiciar a mudança dessas formas de representação e explicação.” (CANDOTTI, 2002, p. 23).

No ensino de ciências nas escolas e na formação de professores, é preciso que se leve em consideração, em última instância, que “[...] se queremos educar um olhar, é preciso descobrir o que ele está vendo.” (CANDOTTI, 2002, p. 23).

\section{REFERÊNCIAS BIBLIOGRÁFICAS}

BOGDAM, R.; BIKLEN, S. Investigação qualitativa em educação: uma introdução a teoria e aos métodos. Porto Editora, 1994.

BRASIL - Instituto Brasileiro de Geografia e Estatatística/IBGE. Disponível em: <http://www.ibge.gov.br>. Acesso em: 30 out. 2006.

CANDOTTI, E. Ciência na educação popular. In: MASSARANI, L.; MOREIRA, I. C.; BRITO, F. Ciência e público: caminhos da divulgação científica no Brasil. Rio 


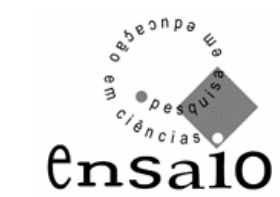

Vol. 11 no 1 junho 2009

de Janeiro: UFRJ, Casa da Ciência - Centro Cultural de Ciência e Tecnologia da Universidade Federal do Rio de Janeiro. Fórum da ciência e Cultura, 2002.

CAPECCHI, M. C. V. de M. Aspectos da cultura científica em atividades de experimentação nas aulas de física. 2004. 264p. Tese de Doutorado, Faculdade de Educação, Universidade de São Paulo, São Paulo, 2004.

COBERN W. W.; AIKENHEAD, G. S. Cultural aspects of learning science. In: International Handbook of Science Education. Great Britain: Kluwer Academic Publishers, p. 39-52, 1998.

CUNHA, J. L.; GÄRTNER, A. (Orgs.). Imigração alemã no Rio Grande do Sul: história, linguagem, educação. Santa Maria, RS: Editora da UFSM, 2003.

GRIGNON, C. Cultura dominante, cultura escolar e multiculturalismo popular. In: SILVA, T. T. da (org.). Alienígenas na sala de aula, $2^{\mathrm{a}}$ ed., Petrópolis, RJ: Vozes, 1998. p. 178-189.

KREUTZ, L. Material didático e currículo na escola teuto-brasileira do Rio Grande do Sul. São Leopoldo: Ed. da Unisinos, 1994a.

MULLER, T. A escola teuto-brasileira católica e a nacionalização do ensino. In: Nacionalização e imigração alemã. São Leopoldo, 1994b.

FIORI, N. A. (Org.). O professor paroquial católico teuto-brasileiro: função religiosa, sociocultural e política. In: _.Etnia e educação: a escola “alemã” do Brasil e estudos congêneres. Florianópolis: Ed. da UFSC; Tubarão: Editora Unisul, 2003a.

KÜLZER, E. (Org.). Síntese histórica do município de Salvador das Missões. Cerro Largo, RS: Gráfica Lenz, 2004.

MEYER, D. E. Etnia, raça e nação: o currículo e a construção de fronteiras e posições sociais. In: COSTA, M. V. (Org.). O currículo nos limiares do contemporâneo, $2^{\mathrm{a}}$ edição, Rio de Janeiro: DP\&A., 1999.

RAMBO, A. B. A escola comunitária teuto-brasileira: a associação dos professores e escola normal. $1^{\text {a }}$ ed., São Leopoldo: Ed. Unisinos, 1996.

FIORI, N. A. (Org.). O teuto-brasileiro e sua identidade. In: Etnia e educação: a escola “alemã” do Brasil e estudos congêneres. Florianópolis: Ed. da UFSC; Tubarão: Editora Unisul, 2003.

UNESCO. Ciência e cidadania: Seminário Internacional Ciência de Qualidade

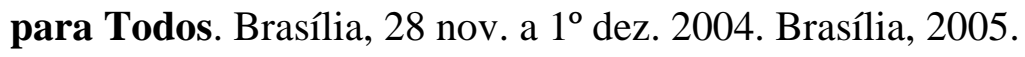




\section{ensaio}

Vol. 11 no 1 junho 2009

VOGT, C. (Org.) Cultura científica: desafios. São Paulo: USP, Fapesp, 2006.

VOGT, C.; POLINO, C. (Orgs.) Percepção pública da ciência: resultados da pesquisa na Argentina, Brasil, Espanha e Uruguai. Campinas, SP: Unicamp, Fapesp, 2003.

WENZEL, E. G. Memória e identidade teuto-brasileira em Cerro Largo, Rio Grande do Sul. Tese (Doutorado), Faculdade de Filosofia, Letras e Ciências Humanas, Universidade de São Paulo, São Paulo, 1997.

Data de recebimento: 07/12/07

Data de aprovação: 14/04/08

Data de versão final: 21/07/08 